\title{
Engineering Corynebacterium crenatum to produce higher alcohols for biofuel using hydrolysates of duckweed (Landoltia punctata) as feedstock
}

\author{
Haifeng Su ${ }^{1 *+}$, Juan Jiang ${ }^{1+}$, Qiuli Lu', Zhao Zhao ${ }^{1}$, Tian Xie ${ }^{1}$, Hai Zhao ${ }^{2^{*}}$ and Maolin Wang ${ }^{1 *}$
}

\begin{abstract}
Early trials have demonstrated great potential for the use of duckweed (family Lemnaceae) as the next generation of energy plants for the production of biofuels. Achieving this technological advance demands research to develop novel bioengineering microorganisms that can ferment duckweed feedstock to produce higher alcohols. In this study, we used relevant genes to transfer five metabolic pathways of isoleucine, leucine and valine from the yeast Saccharomyces cerevisiae into the bioengineered microorganism Corynebacterium crenatum. Experimental results showed that the bioengineered strain was able to produce $1026.61 \mathrm{mg} / \mathrm{L}$ of 2-methyl-1-butanol by fermenting glucose, compared to $981.79 \mathrm{mg} / \mathrm{L}$ from the acid hydrolysates of duckweed. The highest isobutanol yields achieved were $1264.63 \mathrm{mg} / \mathrm{L}$ from glucose and $1154.83 \mathrm{mg} / \mathrm{L}$ from duckweed, and the corresponding highest yields of 3-methyl-1-butanol were 748.35 and 684.79 mg/L. Our findings demonstrate the feasibility of using bioengineered C. crenatum as a platform to construct a bacterial strain that is capable of producing higher alcohols. We have also shown the promise of using duckweed as the basis for developing higher alcohols, illustrating that this group of plants represents an ideal fermentation substrate that can be considered the next generation of alternative energy feedstocks.
\end{abstract}

Keywords: Corynebacterium crenatum, Bioengineering, Duckweed, Higher alcohols

\section{Introduction}

The worldwide decline of fossil fuel reserves in recent years has created an urgent need for the development of new fuel sources, such as bio-alcohols, biohydrogen, biodiesel and the recovery of biomass waste heat [1-5]. Such initiatives to produce alternative energy from renewable materials have the added benefit of addressing the numerous pollution problems that result from fossil fuel consumption [6]. The fermentation of carbohydrates is a well-known way to produce biofuels, and the valueadded fermentation process is also attractive for environmental reasons [3]. An appealing cost-effective approach is the use of the abundant, surplus agricultural waste or

\footnotetext{
*Correspondence: 44036872@qq.com; zhaohai@cib.ac.cn; mlwang@scu.edu.cn ${ }^{\dagger}$ Equal contributors

'Key Laboratory of Bio-resources and Eco-environment of the Ministry of Education, College of Life Sciences, Sichuan University, Chengdu 610064, Sichuan, PR China

${ }^{2}$ Bioenergy Laboratory, Chengdu Institute of Biology, Chinese Academy of Sciences, Chengdu 610041, Sichuan, PR China
}

by-products that represent a source of renewable materials for the production of biofuel [7]. There have been great progresses recently in the production of higher alcohols that have high vapor pressure, low hygroscopicity and high energy density, including isobutanol, 2-methyl1-butanol, octyl alcohol, 3-methyl-1-butanol, and long carbon-chain enol [8].

Higher alcohols have been produced from microorganisms that are used as microbial "cell factories", by improving them with bioengineering traits from other organisms including various yeast species, E.coli $[9,10]$, Corynebacterium glutamicum [1], and Clostridium spp [11]. Such efforts have yielded promising results by replacing the traditional biofuel ethanol with new alternatives, through the use of metabolic engineering to transform metabolic pathways in microorganisms that produce alcohols, or to construct new pathways in microorganisms that do not naturally produce higher

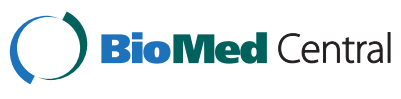


alcohols [12]. The use of bioengineering tools to develop new biofuels has focused primarily on the development and breeding of artificial microbial strains that produce multiple biofuel compounds, such as terpene [13], alkane, higher alcohols efficiently from the substrate of absolute glucose or pentose [14,15]. Recent efforts to so, combined with efforts to optimize the processes for augmenting yields of higher alcohols from glucose, have involved a significant amount of work. However, there has been little success in using bioengineered strains to directly ferment hydrolysates of surplus agricultural waste or plant by-products to produce higher alcohols on an industrial scale. This poses a great challenge to the increased use of non-edible biomass feedstocks as the generation of biofuels. In particular, there are no published assessments of the use of bioengineered microbe strains to directly ferment non-food crop sources, such as duckweed, to produce higher alcohols.

The duckweed family (Lemnaceae) is a group of fastgrowing, floating aquatic species that represent the world's smallest and simplest flowering plants. They have been proposed as an inexpensive, sustainable source of plant biomass for producing biofuels. There are many advantages to using duckweed in this process. For instance, a maximum yield of biomass is obtained in a short time with minimum costs. Its use does not detract from food supplies for human populations, and they can be harvested more easily than algae and other aquatic plants. Compared to other starch feedstocks such as corn and cassava, it is easy to grind, and minimal energy is needed to pretreat it $[16,17]$. Some recent studies have used duckweed as fermentation substrates for the production of ethanol by Saccharomyces cerevisiae $[18,19]$. Current studies have used genetic engineering to remould microorganisms, such as mutant strains of yeast and E.coli, to ferment the hydrolysates of duckweed to produce alcohol, but yields were very low [20]. Therefore, in order to further develop methods for the use of duckweed for the production of higher alcohols, we aimed to develop a microorganism that functions as the better host of bioengineered strains to pair with the fermentation substrates of duckweed.

Although E. coli has proven to be a good expression host in some respects, its overall performance has been hampered by poor tolerance for the end-product, compared to that of coryneform bacteria or fungi such as yeasts, and by poor resistance to the toxic compounds that are found in fermentation substrates after pretreatment processes [21-24]. Therefore, increased attention has been directed at the potential for corynebacterium to possibly act as a better host.

Corynebacterium crenatum is a fast-growing, aerobic, gram-positive, non-sporulating coryneform bacterium. It is often used to produce large quantities of some long- chain amino acids such as leucine, isoleucine and arginine for industrial applications [25-27]. For example, the C. crenatum strain SYPA 5-5 (CGMCC No. 0890) of producing $32.0 \mathrm{~g} / \mathrm{L}$ of L-arginine was obtained by random chemical mutagenesis [28]. The mutant strain $C$. crenatum AS 1.1004 was created by nitrosoguanidine continuous mutagenesis and can also produce L-leucine of $20 \mathrm{~g} / \mathrm{L}$ up to large-scale industrial application [26]. The terminal feedback control function in another mutant strain, C. crenatum AS 1.998, was relieved and no longer subject to inhibition by isoleucine, resulting in yields of up to $14 \mathrm{~g} / \mathrm{L}$ [27]. Corynebacterium glutamicum, however, is usually used to produce short-chain amino acids $\left(<\mathrm{C}_{6}\right)$, such as glutamic acid, valine, lysine in industrial scale production, rather than long-chain amino acids leucine, isoleucine. In this regard, these studies showed that this bacterium has great potential in terms of the production of long-chain amino acids, therefore, signified it may be provide a distinct advantage as an effective "cell factory" for the synthesis of $\mathrm{C}_{5-6}$ higher alcohols via metabolic engineering such as 2-methyl-1-butanol, 3-methyl-1-butanol and 3-methyl1-pentanol. Because these higher alcohols involves some common precursors with amino acids in 2-keto acid pathways, therefore, C. crenatum has shown potential for use in the production of higher alcohols. In this paper, we reported the first use of C. crenatum as an expression host to produce higher alcohols via the use of metabolic engineering to construct strains for that purpose. We also investigated the potential of producing higher alcohols using the hydrolysates of duckweed as fermentation substrates. Our findings provide valuable, fundamental insights that can facilitate further development of methods to use duckweed in the production of higher alcohols as biofuels.

\section{Materials and methods \\ Experimental design}

The purpose of this experiment was to investigate the potential of producing higher alcohols from duckweed, by building an exogenetic metabolic pathway using a "nonnatural" corynebacterium to produce alcohols, C. crenatum. Glucose and duckweed hydrolysate were used as the two fermentation substrates. Experiments were conducted following the methodology illustrated in the flowsheet of fermentation processes (Figure 1). Three replicates of each experiment and assay were conducted, each in a $150-\mathrm{mL}$ triangular flask, unless otherwise indicated.

\section{Bacterial strains, media, and growth conditions}

All plasmids were propagated using E. coli DH5a competent cells (Takara: 9057, Chengdu, China). The E. coli DH5 $\alpha$ bacterial strains were cultivated in LB medium, and grown at $37^{\circ} \mathrm{C}$ in a rotary shaker for $4 \mathrm{~h}$. The bacterium 


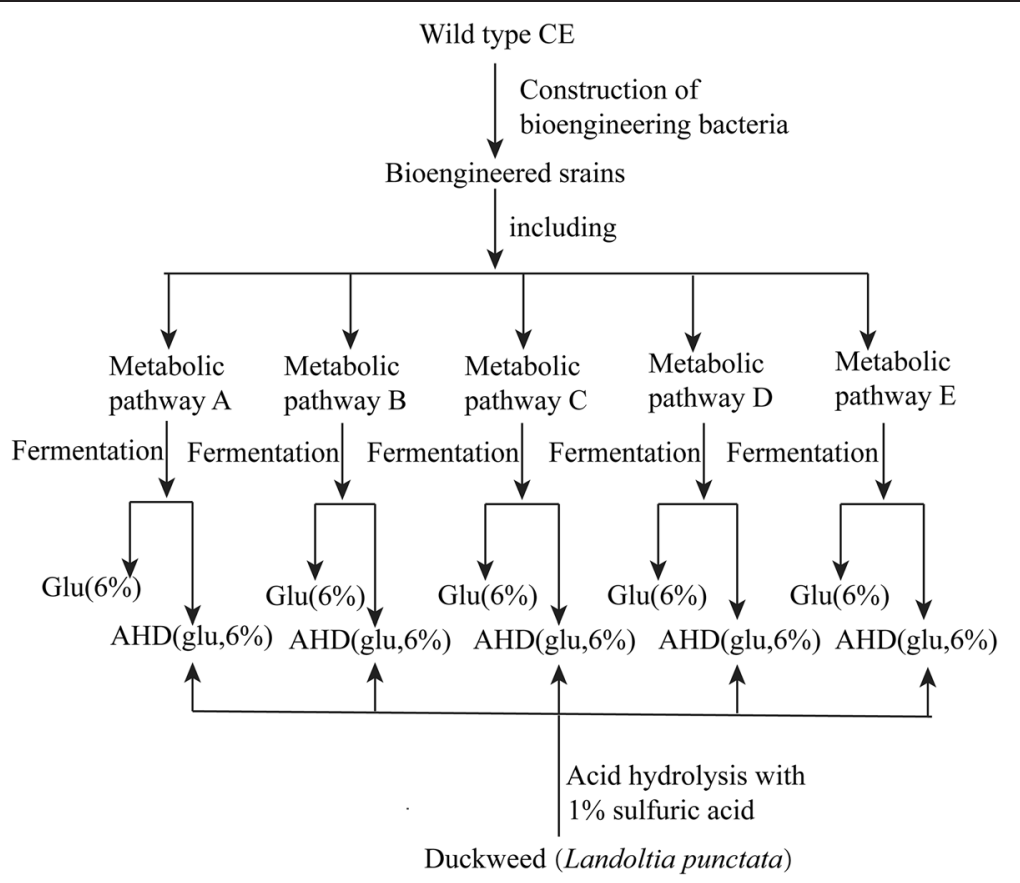

Figure 1 Flowsheet of the design for experimental processes. CE: C. crenatum CICC 20153; Glu: glucose; AHD: acid hydrolysates of duckweed as the fermentation substrate, meaning the products resulting from pretreatment of duckweed with acid hydrolysis.

C. crenatum CICC 20135 was purchased from the China Center of Industrial Culture Collection (CICC, Beijing, China), and rejuvenated and propagated in a nutrition gravy medium (peptone $5.0 \mathrm{~g}$, beef extract $3.0 \mathrm{~g}, \mathrm{NaCl}$ $5.0 \mathrm{~g}$, glucose $20 \mathrm{~g}$, ddH2O $1 \mathrm{~L}, \mathrm{pH} 7.0)$ at $30^{\circ} \mathrm{C}$ in a rotary shaker for $72 \mathrm{~h}$. Cultures of Lactococcus lactis cremoris CICC 1605 were purchased from the CICC and cultivated in MRS medium (peptone $10 \mathrm{~g}$, beef extract $3.0 \mathrm{~g}$, yeast extract $3.0 \mathrm{~g}$, K2HPO4 $2 \mathrm{~g}$, citric acid diamine $2 \mathrm{~g}$, sodium acetate $2 \mathrm{~g}$, glucose $20 \mathrm{~g}, \mathrm{MgSO}_{4} \cdot 7 \mathrm{H}_{2} \mathrm{O} 0.6 \mathrm{~g}, \mathrm{MnSO}_{4}$. $4 \mathrm{H}_{2} \mathrm{O} 0.25 \mathrm{~g}, \mathrm{ddH} 2 \mathrm{O} 1 \mathrm{~L}, \mathrm{pH} 6.2$ ) at $32^{\circ} \mathrm{C}$ in a rotary shaker for $72 \mathrm{~h}$. Cultures of Saccharomyces cerevisiae AH109 were purchased from Clontech Laboratories, Inc. (Beijing, China) and reproduced at $30^{\circ} \mathrm{C}$ in TGY medium in a rotary shaker for $72 \mathrm{~h}$. All cultures of the bioengineered strains of E. coli and C. crenatum CICC 20135 were then induced with $2 \mathrm{mM}$ isopropyl- $\beta$-D-thiogalactoside (IPTG) and grown at $30^{\circ} \mathrm{C}$ for $18 \mathrm{~h}$. Antibiotics (ampicillin, $100 \mu \mathrm{g} / \mathrm{mL}$; chloramphenicol, $35 \mu \mathrm{g} / \mathrm{mL}$; kanamycin, $50 \mu \mathrm{g} / \mathrm{mL}$ ) were added, as needed. The bioengineered strains were reproduced in a rotary shaker under the following conditions: $E$. coli in LB medium at $37^{\circ} \mathrm{C}$ for $12 \mathrm{~h}$, and $C$. crenatum in a nutrition gravy medium at $30^{\circ} \mathrm{C}$ for $48 \mathrm{~h}$, and then moved into $4^{\circ} \mathrm{C}$ to terminate reaction.

\section{Construction of engineered strains of Corynebacterium crenatum CICC 20135}

All Restriction enzymes were purchased from NEB (Shanghai, China) and T4 DNA ligase (EL0334) was supplied by MBI Fermentas (Chengdu, Beijing). Oligonucleotides were ordered from BGI (Beijing, China). The strains of C. crenatum CICC 20135 were constructed as host strains. All strains and plasmids used in the study were listed in Table 1, and the oligonucleotides were listed in Table 2.

The approach used to construct new metabolic pathways was illustrated in Figure 2B. Five metabolic pathways, labelled A (LEU2-ILV2-ILV5), B (ILV2-ILV5-ILV3), C (BAT2), D (LEU4-LEU1), and E (LEU1), were constructed using genes from $S$. cerevisiae AH109. The sixth metabolic pathway, F (Kivd-ADH2) was constructed using the Kivd gene from L. lactis cremoris CICC1605 and the ADH2 gene from S. cerevisiae AH109.

The genes $L E U 2$, ILV2, and ILVS of metabolic pathway A were amplified with the primer pairs A1, A2, and A3, respectively. The genes $I L V 2, I L V 5$ and ILV 3 of pathway B were amplified with the primer pairs B1, B2 and B3, respectively. The gene $B A T 2$ was amplified with the primer pair C1. The genes LEU4 and LEU1 of metabolic pathway D were amplified with the primer pairs D1 and D2. The genes Kivd and ADH2 of metabolic pathway F were amplified with the primer pairs F1 and F2. The gene $L E U 1$ of pathway E was amplified with the primer pair D2, and finally the gene pBL1was amplified with the primer pair G1. The genes Kivd and $A D H 2$ were amplified with the primer pairs $\mathrm{K} 1$, and $\mathrm{H} 1$, respectively.

The plasmids p29-pBL, PEC-KA, p29-AL, p29-ALI, p29-ALII, p29-BI, p29-BII, p29-BIII, p29-CB, p29-DL, 
Table 1 The bacterial strains and vectors used in the bioengineering of bacteria to produce higher alcohols

\begin{tabular}{|c|c|c|}
\hline Strain or plasmid & Relevant genotype & Source \\
\hline \multicolumn{3}{|l|}{ Strains } \\
\hline $\mathrm{DH} 5 \mathrm{a}$ & $\begin{array}{l}\mathrm{F}^{-}, \varphi \text { 80dlacZ } \Delta \mathrm{M} 15, \Delta(\text { lacZYA-argF }) \cup 169 \text {, deo } R \text {, recA1, endA1, hsdR17 } \\
\left(\mathrm{rK}^{-}, \mathrm{mK}^{+}\right) \text {, phoA, supE44, } \lambda^{-}, \text {thi }^{-1}, \text { gyrA96, relA1 }\end{array}$ & Takara: 9057 \\
\hline C. crenatum & ompT, hsdSB $\left(r B^{-} m B^{-}\right), g a l, d c m$ & CICC 20153 \\
\hline \multicolumn{3}{|l|}{ Plasmids } \\
\hline pSTV29 & pACYC184 ori; $\mathrm{Cm}^{\mathrm{r}}$; $\mathrm{PLlaCO}^{-1}$ : MCS & Takara: 3332 \\
\hline p29-pBL & pBL1ori; $\mathrm{Cm}^{\mathrm{r}}$; PLlacO ${ }^{-1}$ : MCS & This study \\
\hline PEC-XK99E & pGA1 Km ${ }^{r}$ pTrc99A MCS P-trc,lacl ${ }^{q}$ & From CAS \\
\hline pXMJ19 & pBL1 ori; Kmr; MCS P-trc, lacl ${ }^{q}$ & From CAS \\
\hline PEC-KA & pGA1 Kmr pTrc99A MCS P-trc, lacla: Kivd(LL)-ADH2(SC) & This study \\
\hline p29- AL & pBL1ori; Cmr; PLlacO-1:MCS:LEU2(SC) & This study \\
\hline p29- ALI & pBL1ori; Cm; PLlacO-1: LEU2(SC)-ILV2(SC) & This study \\
\hline P29- ALII & pBL1 ori; Cm; PLlacO-1: LEU2(SC)-ILV2-ILV5(SC) & This study \\
\hline p29- Bl & pBL1ori; Cmr; PLlacO-1: ILV2(SC) & This study \\
\hline p29- BII & pBL1ori; $\mathrm{Cm}^{\mathrm{r}}$; PLlacO-1 : ILV2(SC)-ILV5(SC) & This study \\
\hline p29- BIII & pBL1 1 ri; $\mathrm{Cm}^{r}$; PLlacO-1. ILV2(SC)-ILV5(SC)-ILV3(SC) & This study \\
\hline p29- CB & pBL1ori; Cmr; PLlacO-1;: BAT2(SC) & This study \\
\hline p29-DL & pBL1 ori; Cmr; PLlacO-1: LEU4(SC) & This study \\
\hline p29-DLL & pBL1 ori; Cmr; PLlacO $^{-1}:$ LEU4(SC)-LEU1(SC) & This study \\
\hline p29-FL & pBL1ori; $\mathrm{Cm}^{\text {r; }}$ PLlacO ${ }^{-1}$ : LEU1(SC) & This study \\
\hline
\end{tabular}

SC: S. cerevisiae AH109; LL: Lactococcus lactis subsp. cremoris CICC 1605.

p29-DLL, p29-FL and p29-FLL were constructed as follows. The gene $p B L 1$ from the vector pXMJ19 was inserted into vector pSVT29 using the restriction enzymes sacII and ClaI to construct plasmid p29-pBL. The in-series genes $K I V D-A D H 2$ were inserted into vector PEC-XK99E using restriction enzymes PstI, XbaI, KpnI to construct plasmid PEC-KA. The in-series genes LEU2-ILV2-ILV5 were inserted into vector p29-pBL using restriction enzymes sphI, SalI, BamHI, sacI and T4 ligase to construct plasmids p29-AL, p29-ALI and p29-ALII. The in-series genes ILV2-ILV5-ILV3 were inserted into vector p29-pBL using restriction enzymes pstI, SalI, BamHI, sacI and T4 ligase to construct plasmids p29-BI, p29-BII, p29-BIII. The gene BAT2 was inserted into vector $\mathrm{p} 29-\mathrm{pBL}$ using restriction enzymes sbfl, BamHI and T4 ligase to construct plasmid p29-CB. The in-series genes LEU4-LEU1 were inserted into vector p29-pBL using restriction enzymes sbfl, $x m a \mathrm{I}, s a c \mathrm{I}$ and T4 ligase to construct plasmids p29-DL and p29DLL. The gene LEU1 was inserted into vector p29-pBL using restriction enzymes $s b f \mathrm{l}, \mathrm{Bam} \mathrm{HI}$ and T4 ligase to construct plasmid p29-FL. The ribosome binding site (RBS) sequence was inserted at the position 6-8 nucleotides upstream of each structural gene to facilitate mRNA translation.

The preparation of competence cells of C. crenatum was described in the Handbook of Corynebacterium glutamicum [29]. All construction plasmids were introduced into $C$. crenatum using the electroporation proto-

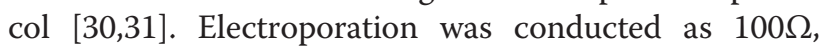
$50 \mu \mathrm{F}, 2.2 \mathrm{kV}, 8 \mathrm{~ms}$ with Gene Pulser Xcell Microbial System165-2662 (BIO-RAD, Chengdu).

\section{Genes expression analysis}

Genes expression of all recombinant genes for each metabolic pathway in the production host were analyzed using semi-quantitative RT-PCR. RNA extraction and cDNA synthesis were prepared according to operation manual of TransScript First-Strand cDNA Synthesis SuperMix kit of the manufacturer (TransGen Biotech, Beijing, China). Semi-quantitative RT-PCR analysis: Expression profile of all recombinant genes were evaluated based on semi-quantified analysis system using Gel-Pro analyzer 4.0 software (Media Cybernetics, Silver Spring, $\mathrm{MD})$, the calculated result of all exogenous genes expression was indicated using integral optical density (IOD).

\section{Pretreatment processing of dried duckweed}

Duckweed (wild Landoltia punctata) was collected opportunistically from the surface of wild ponds in Huilong Town, Xinjin County, Chengdu, China. The fresh plants were dried at $60^{\circ} \mathrm{C}$ with drying oven(DHP9050A, Shanghai, China), crushed into powder with (FS100S-3, Guangzhou, 
Table 2 Primers used in the bioengineering of bacteria to produce higher alcohols

\begin{tabular}{|c|c|c|}
\hline Number & Primers name & Primer 5'-3' \\
\hline \multirow[t]{2}{*}{ A1 } & LEU2-S & ACATGCATGCGGATGTCTGCCCCTAAGAAGAT \\
\hline & LEU2-AS & ACGCGTCGACTTAAGCAAGGATTTTCTTAACTTC \\
\hline \multirow[t]{2}{*}{ A2 } & ILV2-S & ACGCGTCGACAAGGAGCCAGATGATCAGACAATCTACGCT \\
\hline & ILV2-AS & CGCGGATCCTCAGTGCTTACCGCCTGTAC \\
\hline \multirow[t]{2}{*}{ A3 } & ILV5-S & CGCGGATCCAAGGAGGCCTCATGTTGAGAACTCAAGCCGC \\
\hline & ILV5-AS & GCGAGCTCTTATTGGTTTTCTGGTCTCAACTT \\
\hline \multirow[t]{2}{*}{ B1 } & ILV2-S & AAAACTGCAGATGATCAGACAATCTACGCT \\
\hline & ILV2-AS & ACGCGTCGACTCAGTGCTTACCGCCTGTAC \\
\hline \multirow[t]{2}{*}{ B2 } & ILV5-S & ACAGGTCGACAAGGAGGTCATGTTGAGAACTCAAGCCGC \\
\hline & ILV5-AS & CGCGGATCCTTATTGGTTTTCTGGTCTCAA \\
\hline \multirow[t]{2}{*}{ B3 } & ILV3-S & CGCGGATCCAAGGAGCTGCATGGGCTTGTTAACGAAAGT \\
\hline & ILV3-AS & GCGAGCTCTCAAGCATCTAAAACACAACC \\
\hline \multirow[t]{2}{*}{ C1 } & BAT2-S & CGGCCTGCAGGATGACCTTGGCACCCCTAGA \\
\hline & BAT2-AS & CGCGGATCCTCAGTTCAAATCAGTAACAA \\
\hline \multirow[t]{2}{*}{ D2 } & LEU1-S & TCCCCCCGGGAAGGAGACTAATGGTTTACACTCCATCCAA \\
\hline & LEU1-AS & GCGAGCTCCTACCAATCCTGGTGGACTTT \\
\hline \multirow[t]{2}{*}{ C2 } & leu1-2as & CGCGGATCCAAAGGAGGCCGCATGGTITACACTCCATCCAAGG \\
\hline & leu1-2s & TCCCCCCGGGCTACCAATCCTGGTGGACTIT \\
\hline \multirow[t]{2}{*}{ C3 } & leu2-2s & TCCCCCCGGGAAAGGAGGCCGCATGTCTGCCCCTAAGAAGATC \\
\hline & leu2-2as & GCGAGCTCTTAAGCAAGGATTTCTTAAC \\
\hline \multirow[t]{2}{*}{ D1 } & leu4-2as & CGGCCTGCAGGATGGTTAAAGAGAGTATTAT \\
\hline & leu4-2s & TCCCCCCGGGTTATGCAGAGCCAGATGCCG \\
\hline \multirow[t]{2}{*}{ D2 } & LEU1-S & TCCCCCCGGGAAGGAGACTAATGGTTTACACTCCATCCAA \\
\hline & LEU1-AS & GCGAGCTCCTACCAATCCTGGTGGACTTT \\
\hline \multirow[t]{2}{*}{ F1 } & leu1-2 s & CGGCCTGCAGGATGGTTTACACTCCATCCAA \\
\hline & leu1-2as & CGCGGATCCCTACCAATCCTGGTGGACTT \\
\hline \multirow[t]{2}{*}{ G1 } & pBL1-as & TCCCCGCGGATTCGGGGTCGTTCACTGGT \\
\hline & pBL1-s & CCATCGATAACAACAAGACCCATCATAG \\
\hline \multirow[t]{2}{*}{$\mathrm{K} 1$} & Kivd-s & AAAACTGCAGATGTATACAGTAGGAGATTACCT \\
\hline & Kivd-as & GCTCTAGATTATGATTTATTTTGTTCAGC \\
\hline \multirow[t]{2}{*}{$\mathrm{H} 1$} & $\mathrm{ADH} 2-\mathrm{s}$ & GCTCTAGAAGGAAACTCAATGTCTATTCCAGAAACTCAA \\
\hline & ADH2-as & CGGGGTACCTTATTTAGAAGTGTCAACAACG \\
\hline
\end{tabular}

$\mathrm{s}=$ sense and as $=$ antisense.

China), and then hydrolyzed with $1 \% \mathrm{H}_{2} \mathrm{SO}_{4}$. The starch content was calculated based on the total sugar content $($ starch content $=$ glucose content $\times 0.91) \quad[32,33]$. The crude protein content was measured as $\mathrm{CP}=\mathrm{K}_{\mathrm{j}} \mathrm{N} \times 6.25$ $[34,35]$. Cellulose content was measured with spectrophotometry: a 10-g sample of duckweed was placed in $1 \mathrm{~L}$ water, $60 \mathrm{~mL}$ of $60 \% \mathrm{H}_{2} \mathrm{SO}_{4}$ were added, and the plants were left to decompose for $30 \mathrm{~min}$. We added $2 \%$ anthrone reagent $(\mathrm{v} / \mathrm{v})$ to the hydrolyzed mixture, left it for $2 \mathrm{~min}$, and then measured the absorbance at $620 \mathrm{~nm}$ [36-38]. We then calculated the cellulose content of samples according to a standard curve, using the formula: cellulose content $\mathrm{Y}(\%)$ of duckweed $=\mathrm{X}$ (cellulose content of standard sample) $\times$ a (diluted multiples) $\times$ $100 / W$ (total weight of samples). The content of lignin was determined using acetyl bromide according to standard methods $[39,40]$. The resulting components of duckweed were listed in Table 3.

Duckweed substrates were pretreated using established methods of acid hydrolysis [20]. The products of hydrolysis were then fermented by bioengineeried strains of $C$. crenatum. The initial total glucose content of the pretreated duckweed was adjusted to $60 \pm 2.61 \mathrm{~g} / \mathrm{L}$, and the $\mathrm{pH}$ of hydrolysates was adjusted to 6.7 using $0.1 \%$ $\mathrm{Ca}(\mathrm{OH})_{2}$. The liquefied hydrolysates of duckweed were then used as the substrate for further fermentation 


\section{A}

Reductive amination

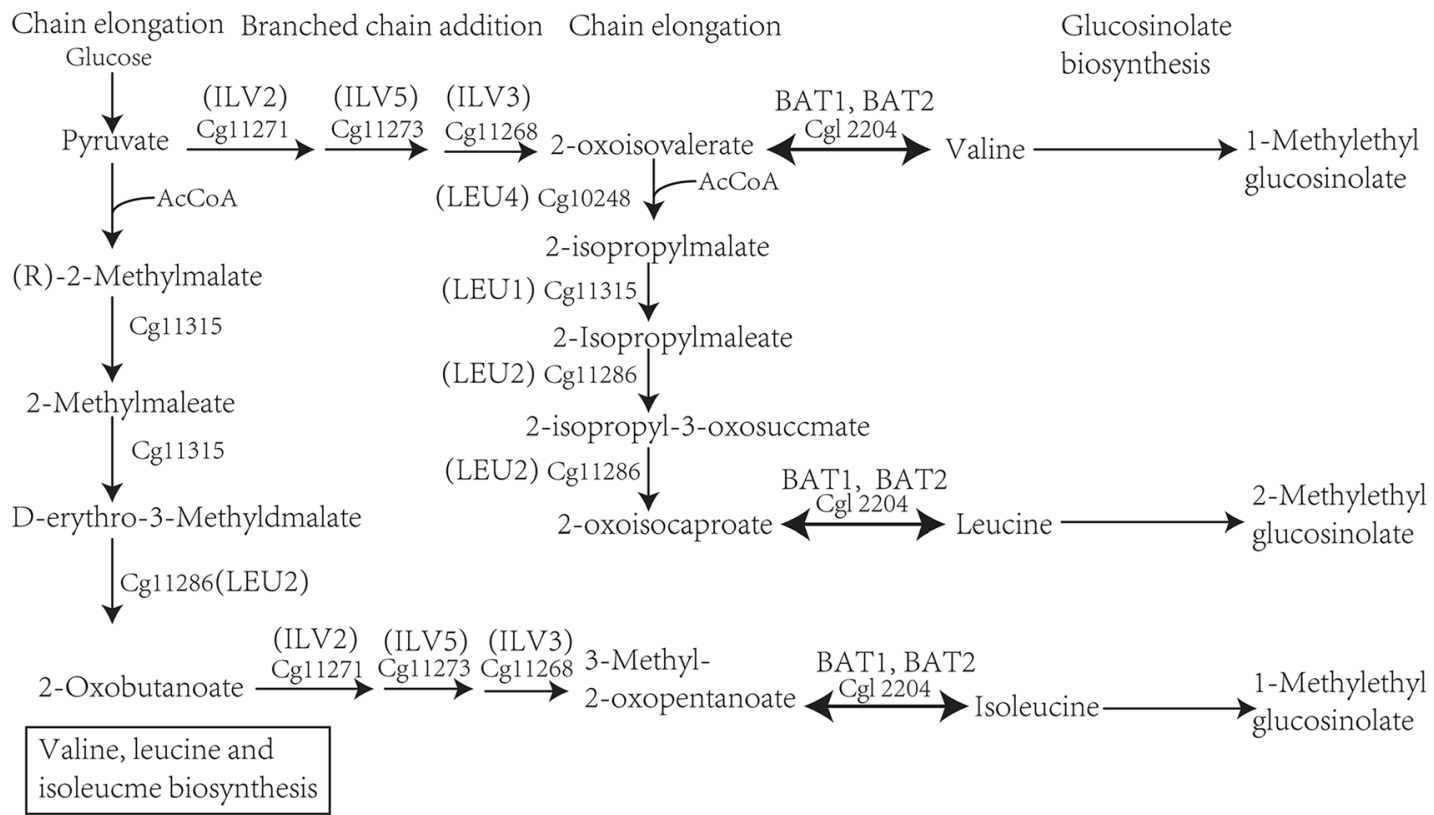

B

B

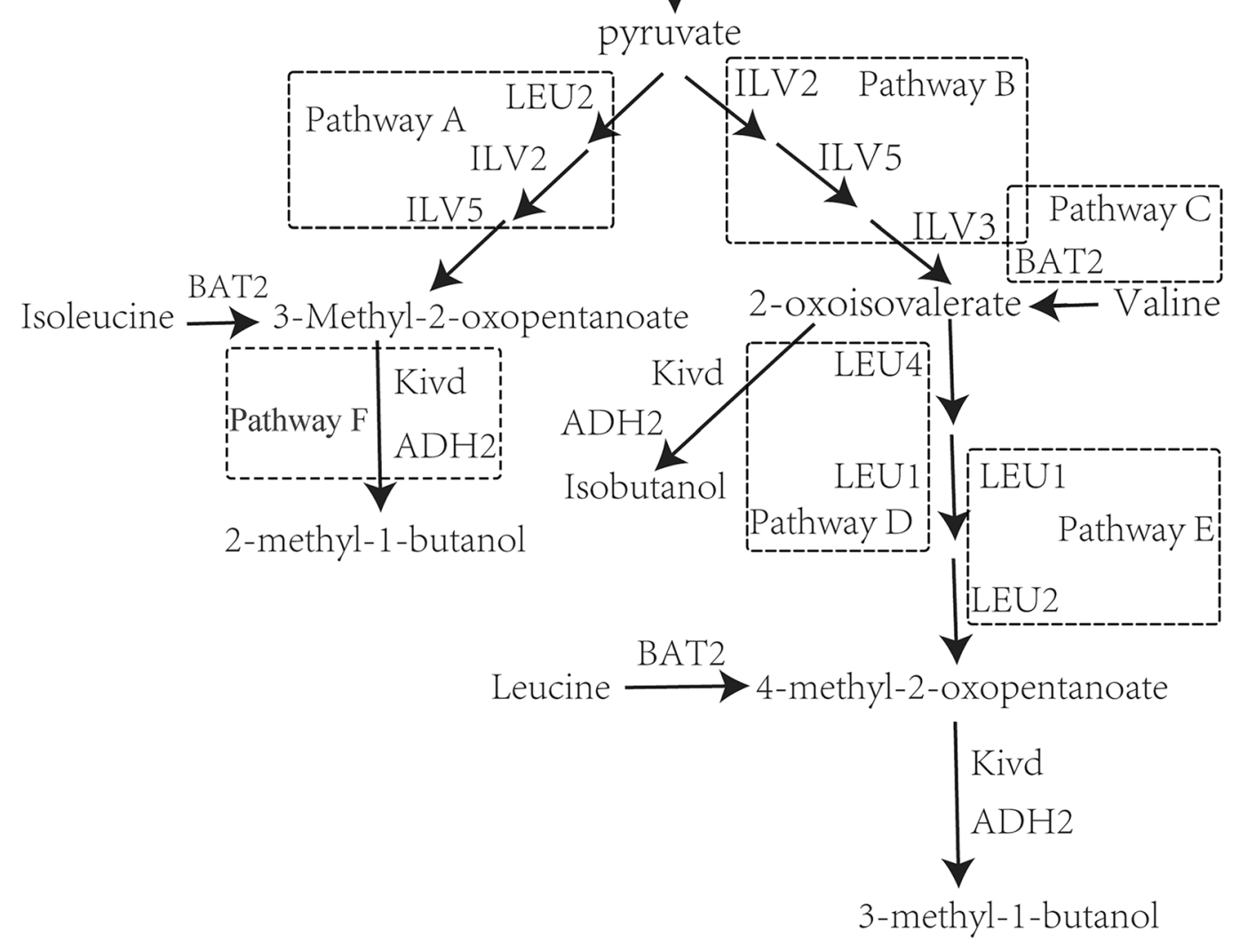

Figure $\mathbf{2}$ (See legend on next page.) 
(See figure on previous page.)

Figure 2 The metabolic pathways of 2-keto acid compounds and construction of the biological synthesis pathways in bioengineered strains for producing higher alcohols via fermentation by microbes. A: the common schematic pathways of S. cerevisiae (2-Oxocarboxylic acid metabolism: http://www.genome.jp/dbget-bin/www_bget?pathway:sce01210) and C. crenatum for producing 2-keto acid compounds. The genes LEU2, ILV5, ILV2, ILV3, LEU4, LEU1, BAT1 and BAT2 play a role in the synthesis of 2-keto acids in S. cerevisiae. The genes Cgl 1315, Cgl 1286, Cgl 1271, Cgl 1273, Cgl 1268, Cg1 0248 and Cgl 2204 act as catalysts in the production of 2-keto acids in C. crenatum. LEU2, Cgl 1286:3-isopropylmalate dehydrogenase. ILV5, Cgl 1273:ketoacid reductiove isomerase. ILV2, Cgl 1271:acetyl lactic acid synthase. ILV3, Cgl 1268: dihydroxy acid dehydratase. LEU4, Cg1 0248:2-isopropyl malic acid synthase. LEU1, Cgl 1315: 3-isopropylmalate dehydratase. BAT1, BAT2, Cgl 2204: branched-chain amino acid transaminase. B: construction of the metabolic pathways for higher alcohol production in C. crenatum based on 2-Keto acid pathways; ADH2: Alcohol dehydrogenase; Kivd: alpha-ketoisovalerate decarboxylase. Metabolic pathway A: LEU2-ILV2-ILV5 + KIVD-ADH2; Metabolic pathway B: ILV2-ILV5-ILV3 + KIVD-ADH2; Metabolic pathway C: BAT2 + KIVD-ADH2; Metabolic pathway D: LEU4-LEU1 + KIVD-ADH2; Metabolic pathway E: LEU1 + KIVD-ADH2.

experiments; their carbohydrate composition (i.e., after pretreatment, at $0 \mathrm{~h}$ of fermentation) was presented in Table 3.

\section{Fermentation conditions and process}

In order to evaluate the effect of using different fermentation substrates, the experiments were divided into two parts: part one used the traditional substrate of glucose, to provide a basis for comparison, and part two was conducted using the hydrolysates of duckweed.

The fermentation substrate in glucose trials was $60 \mathrm{~g} / \mathrm{L}$ glucose, combined with a Trace Metals Mix solution $\left(\mathrm{NaCl} 5 \mathrm{~g} / \mathrm{L},(\mathrm{NH} 4)_{2} \mathrm{SO}_{4} 20 \mathrm{~g} / \mathrm{L}, \mathrm{KH}_{2} \mathrm{PO}_{4} 1.5 \mathrm{~g} / \mathrm{L}, \mathrm{MgSO}_{4}\right.$. $7 \mathrm{H}_{2} \mathrm{O} 0.3 \mathrm{~g} / \mathrm{L}, \mathrm{FeSO}_{4} \cdot 7 \mathrm{H}_{2} \mathrm{O} 0.05 \mathrm{~g} / \mathrm{L}, \mathrm{MnSO}_{4} \cdot \mathrm{H}_{2} \mathrm{O}$ $0.01 \mathrm{~g} / \mathrm{L}, \mathrm{CH}_{3} \mathrm{COONH} 1.0 \mathrm{~g} / \mathrm{L}$ ) that contained $10 \mathrm{~g} / \mathrm{L}$ peptone and $5 \mathrm{~g} / \mathrm{L}$ yeast extract.

The fermentation substrate in duckweed trials was hydrolysates of duckweed in $20 \mathrm{~mL}$ of modified M9 medium $\left(2 \mathrm{~g}\left(\mathrm{NH}_{4}\right)_{2} \mathrm{PO}_{4}, 2 \mathrm{~g} \mathrm{KH} \mathrm{PO}_{4}, 1 \mathrm{~g} \mathrm{~K}_{2} \mathrm{HPO}_{4}, 1 \mathrm{~g}\right.$ $\mathrm{NH}_{4} \mathrm{Cl}, 0.5 \mathrm{~g} \mathrm{NaCl}, 0.5 \mathrm{mM} \mathrm{MgSO}, 1 \mathrm{mM} \mathrm{CaCl}$, $20 \mathrm{mg}$ vitamin $\mathrm{B} 1$, and $2 \mathrm{mg}$ biotin per $\mathrm{L}$ of water) containing $5 \mathrm{~g} / \mathrm{L}$ yeast extract, $10 \mathrm{~g} / \mathrm{L}$ peptone and Trace Metals Mix solution $\left(2 \mathrm{~g} \mathrm{H}_{3} \mathrm{BO}_{3}, 2.1 \mathrm{~g} \mathrm{MnCl}_{2} \cdot 4 \mathrm{H}_{2} \mathrm{O}\right.$, $0.3 \mathrm{~g} \mathrm{ZnSO}_{4} \cdot 7 \mathrm{H}_{2} \mathrm{O}, 0.002 \mathrm{~g} \mathrm{MnSO}_{4} 2.5 \mathrm{~g}, \mathrm{Na}_{2} \mathrm{MoO}_{4}$. $2 \mathrm{H}_{2} \mathrm{O}, 0.05 \mathrm{~g} \mathrm{CuSO}_{4} \cdot 5 \mathrm{H}_{2} \mathrm{O}, 21.2 \mathrm{mg} \mathrm{Co}\left(\mathrm{NO}_{3}\right) 2 \cdot 6 \mathrm{H}_{2} \mathrm{O}$, and $0.05 \mathrm{~g} \mathrm{FeSO}_{4}$ per L of water) in a $150-\mathrm{mL}$ triangular flask.

The substrates were fermented under aerobiotic condition; and $2 \mathrm{~mL}$ of a rejuvenated seeding solution from liquid medium was inoculated into $50 \mathrm{~mL}$ of the acid hydrolysates in a $150 \mathrm{~mL}$ triangular flask. All cultures were induced with $2 \mathrm{mM}$ IPTG, kanamycin, and chloramphenicol, kept at $30^{\circ} \mathrm{C}$ to allow $4 \mathrm{~h}$ of growth, and then fermented at $30^{\circ} \mathrm{C}$ with shaking at $200 \mathrm{rpm}$ for 96 hours in a constant-temperature oscillation incubator. The initial $\mathrm{pH}$ values of fermentation substrates were adjusted to 7.0.

\section{Detection of alcohols produced from fermentation}

Alcohol compounds were measured with a model 6890 gas chromatograph (GC) equipped with a flame ionization detector (Agilent Technologies, Santa Clara, CA, USA) with a model 7673A automatic injector, sampler, and controller (Hewlett-Packard). Alcohol compounds were separated out using a ZB-WAX capillary column ( $30 \mathrm{~m}, 0.25 \mathrm{~mm}$ inside diameter, $0.25 \mu \mathrm{m}$ film thickness; Phenomenex Inc., PA, USA). The GC oven temperature was held initially at $40^{\circ} \mathrm{C}$ for $5 \mathrm{~min}$, and then raised stepwise, by $15^{\circ} \mathrm{C} / \mathrm{min}$, until it reached $150^{\circ} \mathrm{C}$. It was then raised by $50^{\circ} \mathrm{C} / \mathrm{min}$ up to $250^{\circ} \mathrm{C}$, and held for $4 \mathrm{~min}$. Helium was used as the carrier gas, with an inlet pressure of $9.3 \mathrm{lb} / \mathrm{in}^{2}$. The injector and detector were maintained at $220^{\circ} \mathrm{C}$. A $1-\mu \mathrm{L}$ volume of supernatant from the culture broth was injected in splitinjection mode at a 1:30 split ratio. For other secreted metabolites, the constituent compounds $(20 \mu \mathrm{L})$ were detected with an Agilent 1100 high-performance liquid chromatography system equipped with an auto-sampler and a Bio-Rad (Hercules, CA: carbohydrate analysis column Aminex HPX-87P Column $300 \times 7.8 \mathrm{~mm}$ catalog

Table 3 The main components and carbohydrate composition after pretreatment with acid hydrolysis of wild duckweed Landoltia punctata(before fermentation: $0 \mathrm{~h}$ )

\begin{tabular}{|c|c|c|c|c|c|}
\hline Pretreatment sample & Cellulose content & Protein content & Starch content & Lignin content & \\
\hline \multicolumn{6}{|l|}{ Main components } \\
\hline Dried duckweed & $26.64 \%$ & $23.71 \%$ & $31.31 \%$ & $1.89 \%$ & \\
\hline Fresh duckweed & $3.81 \%$ & $3.12 \%$ & $4.32 \%$ & $0.038 \%$ & \\
\hline \multicolumn{6}{|c|}{ Carbohydrate production after acid hydrolysis } \\
\hline Pretreatment sample & Glucose & xylose & Galactose & Fructose & Arabinose \\
\hline Dried duckweed ${ }^{a}$ & $5.22 \pm 0.28$ & $1.03 \pm 0.055$ & $0.49 \pm 0.088$ & $0.72 \pm 0.21$ & $0.46 \pm 0.24$ \\
\hline Fresh duckweed $^{a}$ & $0.61 \pm 0.14$ & $0.094 \pm 0.11$ & $0.044 \pm 0.013$ & $0.121 \pm 0.016$ & $0.094 \pm 0.007$ \\
\hline
\end{tabular}

Content (g) of various components measured in $10 \mathrm{~g}$ pretreatment samples. ${ }^{a}$ Acid hydrolysis pretreatment method. 
125-0098 serial 426070) (5 mM H $\mathrm{H}_{2} \mathrm{SO}_{4}, 0.6 \mathrm{~mL} / \mathrm{min}$; column temperature at $65^{\circ} \mathrm{C}$ ). Glucose was detected with an ELSD 2000 CSC detector, while organic acids were detected using a photodiode array detector at $210 \mathrm{~nm}$. Concentrations were determined using extrapolation from standard curves.

Inhibitors: glucuronic acid, p-coumaric acid, syringic acid, ferulic acid were determined with a DIONEX UltiMate 3000 liquid chromatograph in a column packed with Aminex HPX-87H and $0.05 \mathrm{mM} \mathrm{H}_{2} \mathrm{SO}_{4}$ on Chromosorb WAW. The chromatography was conducted at an injector temperature of $175^{\circ} \mathrm{C}$, detector temperature of $180^{\circ} \mathrm{C}$, and oven temperature of $125^{\circ} \mathrm{C}$. Determination of furfural and 5-Hydroxymethylfurfural were determined with HPLC according to the methods $[41,42]$.

\section{Statistical analysis}

For each experiment and assay, we calculated the mean response variables and their standard deviation (SD), unless otherwise indicated. Comparisons of variable(s) were made with Student's t-test; values of $\mathrm{P}<0.05$ were considered to indicate significant differences. Multiple comparisons were made using the LSD. Tukey's honest significant difference test was used when the null hypothesis was rejected $(\mathrm{P}<0.05)$. Statistical analyses were conducted using the software program SPSS 21.0 (IBM, USA).

\section{Results}

In this study, the interrelated genes that control the metabolic pathways of isoleucine, leucine and valine
(Figure 2A) were overexpressed into the host C. crenatum in order to enable it to produce higher alcohols. First, the success of all exogenous genes expression were confirmed by RT-PCR assay. The results of RT-PCR assay were further semi-quantitatively estimated using Gel-Pro Analyzer 4.0 software (Figure 3). Our results demonstrated that the expression quantity of recombinant genes for each metabolic pathway remained relatively different at same induction condition. We then investigated the potential of the bioengineered strains to produce higher alcohols from the hydrolysates of duckweed, as a way to use the plant as feedstock for a source of alternative energy. To verify whether the bioengineered strains were able to produce higher alcohols at all, we first investigated their potential using $60 \mathrm{~g} / \mathrm{L}$ of glucose as the fermentation substrate for $96 \mathrm{~h}$.

The fermentation results achieved using metabolic pathway A (mpA) that we constructed are shown in Figure 4. The highest yield of 2-methyl-1-butanol (1026.61 mg/L) was obtained when three serial genes LEU2-ILV2-ILV5 (mpA, p29-ALII) were overexpressed in C. crenatum using glucose as the fermentation substrate (Figure 4A, Table 4). Similarly, the bioengineered strain with those three genes produced the highest yield of 2-methyl-1-butanol (981.79 mg/L) from the hydrolysates of duckweed. However, the yield was clearly lower in the pathways that contained two serial genes (p29-ALI), dropping to $661.79 \mathrm{mg} / \mathrm{L}$ with glucose (Figure 4A) and to $541.13 \mathrm{mg} / \mathrm{L}$ with duckweed (Figure 4B). The yield of 2-methyl-1-butanol obtained when the bioengineered strain had only one overexpressed gene (p29-AL) was approximately $200 \mathrm{mg} / \mathrm{L}$. We also investigated changes in the production of isobutanol and 3-methyl-1-butanol.

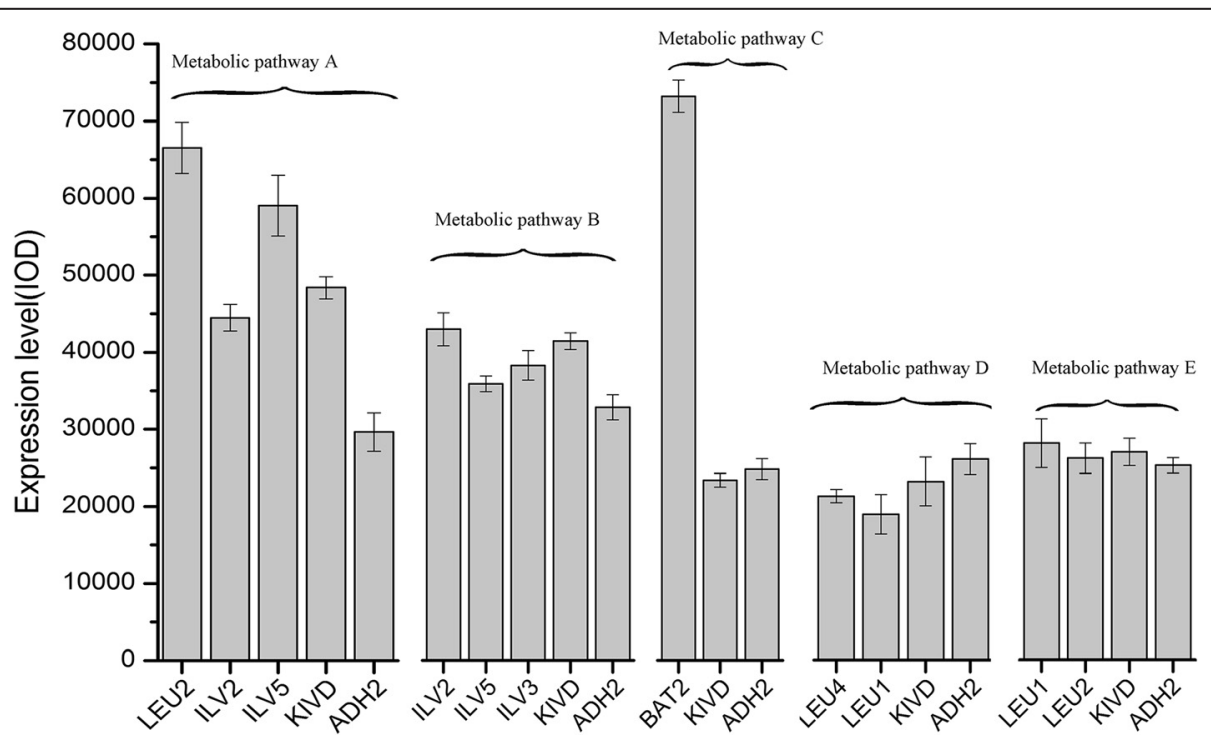

Figure 3 Genes expression of all recombinant genes for each metabolic pathway in the production host were analyzed using semi-quantitative RT-PCR. Semi-quantitative RT-PCR analysis: Expression profile of all recombinant genes were evaluated using Gel-Pro analyzer 4.0 software. 


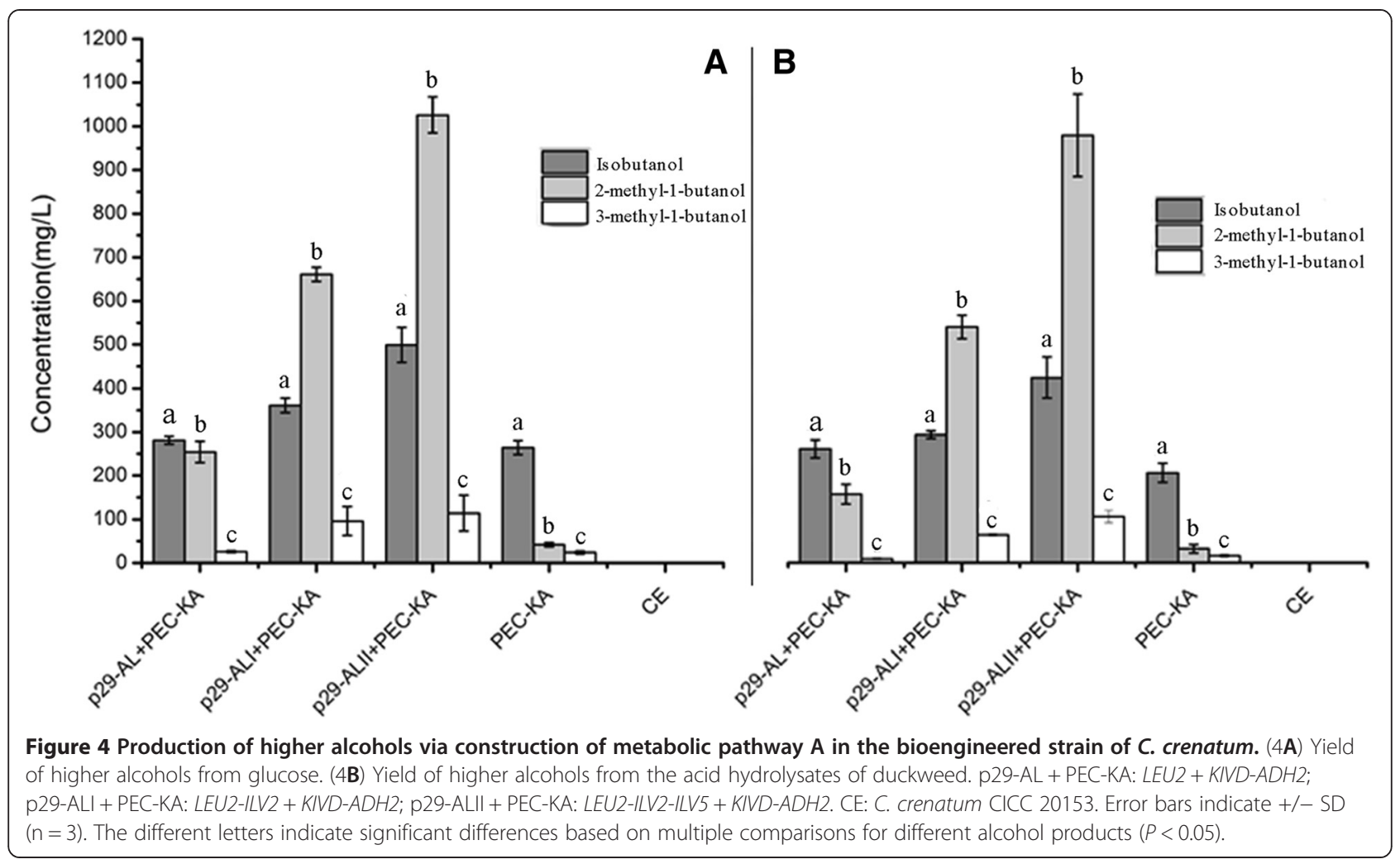

Even when only one gene (LEU2) was overexpressed, the 2methyl-1-butanol yield improved noticeably, while the yields of isobutanol and 3-methyl-1-butanol did not improve (Figure 4). Thus, the yields of three kinds of high alcohols had improved to a certain extent when the serial genes $L E U 2-I L V 2$ were overexpressed. In particular, the yield of 2-methyl-1-butanol increased significantly when the three genes in series LEU2-ILV2-ILV5 were overexpressed, but the yield of isobutanol did not increase.

Maximum isobutanol yields were achieved with both substrates $(1264.63 \mathrm{mg} / \mathrm{L}$ from glucose, and $1154.83 \mathrm{mg} / \mathrm{L}$ from duckweed) when the bioengineered strain contained three serial genes (metabolic pathway B, p29-BIII). The second highest yields of that product were $641.58 \mathrm{mg} / \mathrm{L}$ (Figure 5A, Table 4) and $581.28 \mathrm{mg} / \mathrm{L}$ (Figure 5B) achieved with glucose and duckweed substrates, respectively. The bioengineered strain that contained p29-BI (ILV2) produced $\sim 300 \mathrm{mg} / \mathrm{L}$ of isobutanol, regardless of the fermentation substrate, which did not improve upon the yield of $206.69 \mathrm{mg} / \mathrm{L}$ achieved with the strain that contained only the vector PEC-KA. We also noted changes in the production of other higher alcohols such as 2-methyl-1-butanol and 3-methyl-1butanol. The yields of isobutanol did not obviously improve when only the gene ILV2 was overexpressed, but the yields of 2-methyl-1-butanol and 3-methyl-1-butanol did improve. Yields of three higher alcohols improved when the two serial genes ILV2-ILV5 were overexpressed in $C$. crenatum. This result was especially enhanced when the three serial genes ILV2-ILV5ILV3 were overexpressed simultaneously: the yield of isobutanol increased, while the yield of 3-methyl-1-butanol did not improve (Figure 5).

Isobutanol yields were improved markedly by introduction of the gene BAT2 (metabolic pathway C, p29$\mathrm{CB}$ ) into $C$ crenatum, reaching $286.35 \mathrm{mg} / \mathrm{L}$ from glucose (Figure 6A) and $262.18 \mathrm{mg} / \mathrm{L}$ from duckweed (Figure 6B).

Table 4 The highest yield of higher alcohols produced via bioengineered strains corresponding to relevant metabolic pathways

\begin{tabular}{|c|c|c|c|}
\hline Bioengineered strains & Isobutanol (mg/L) & 2-methyl-1-butanol (mg/L) & 3-methyl-1-butanol (mg/L) \\
\hline Strain with p29-BIII + PEC-KA & $1264.633_{a}^{a} / 1154.83 \frac{b}{a}$ & $589.43_{a}^{a} / 492.76_{a}^{a}$ & $117.27_{a}^{a} / 101.62_{a}^{b}$ \\
\hline Strain with p29-ALII + PEC-KA & $499.31 \frac{a}{b} / 425.71 \frac{b}{b}$ & $1026.61 \frac{a}{b} / 981.79 \stackrel{b}{b}$ & $114.86_{a}^{a} / 106.24_{a}^{b}$ \\
\hline Strain with p29-DLL + PEC-KA & $306.57_{c}^{a} / 228.49_{c}^{b}$ & $234.76_{c}^{a} / 118.63_{c}^{b}$ & $748.35_{b}^{a} / 684.79 \stackrel{b}{b}$ \\
\hline
\end{tabular}

${ }^{a}$ the highest yield from glucose; ${ }^{b}$ the highest yield from acid hydrolysates of duckweed.

$a, b, c$ different letters in table indicate significant differences based on multiple comparisons $(P<0.05)$. 


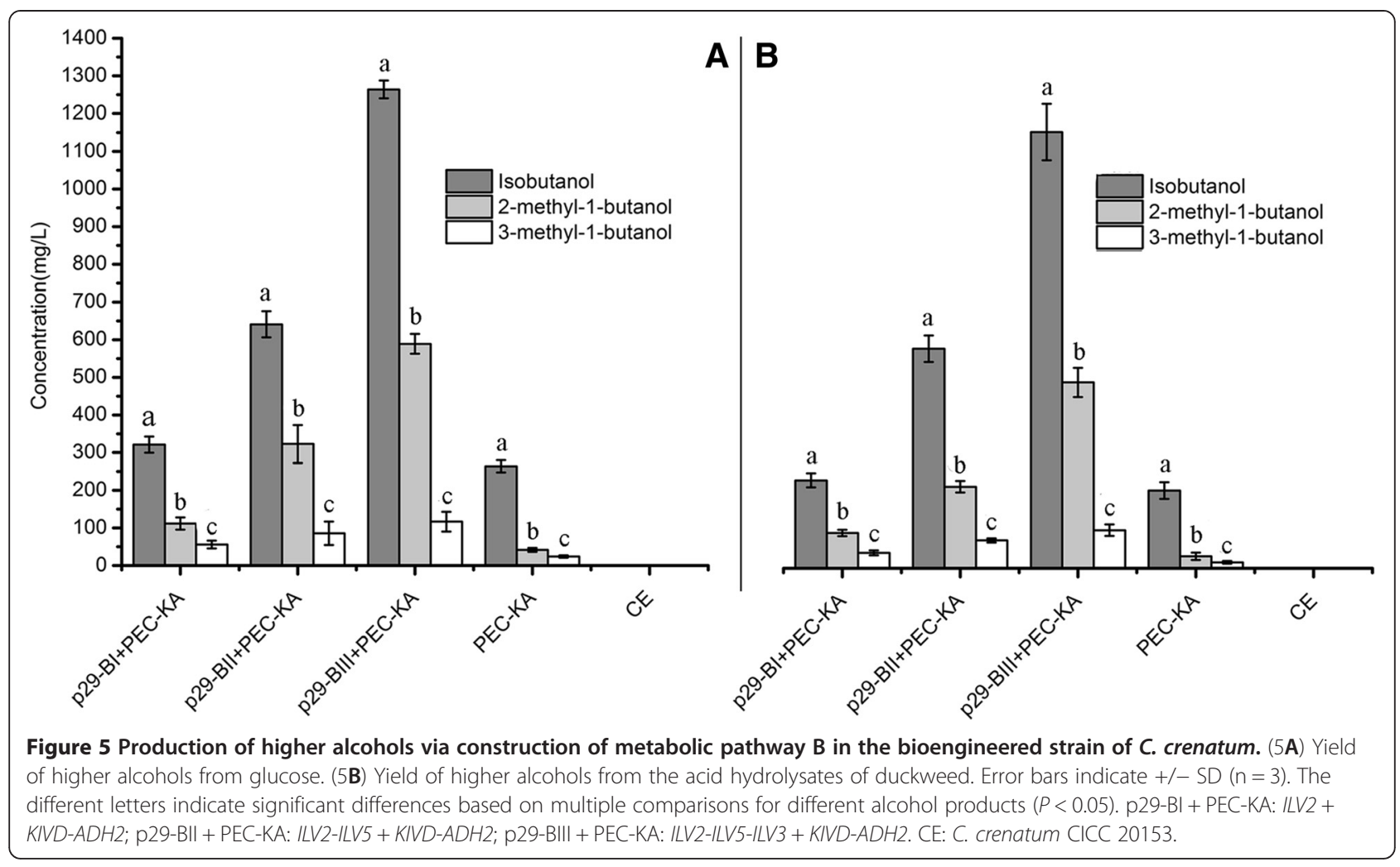

Further, overexpressing the gene $B A T 2$ resulted in a higher relative proportion of 2-methyl-1-butanol and 3methyl-1-butanol in the total yield versus 3-methyl-1butanol (Figure 6). Overall though, there were greater impacts on isobutanol than on yields of the other two kinds of alcohol, so we infer that the gene $B A T 2$ plays an important role in the production of isobutanol when new metabolic pathways are constructed.

When metabolic pathway D was used, the highest yield of 3-methyl-1-butanol was obtained when the serial

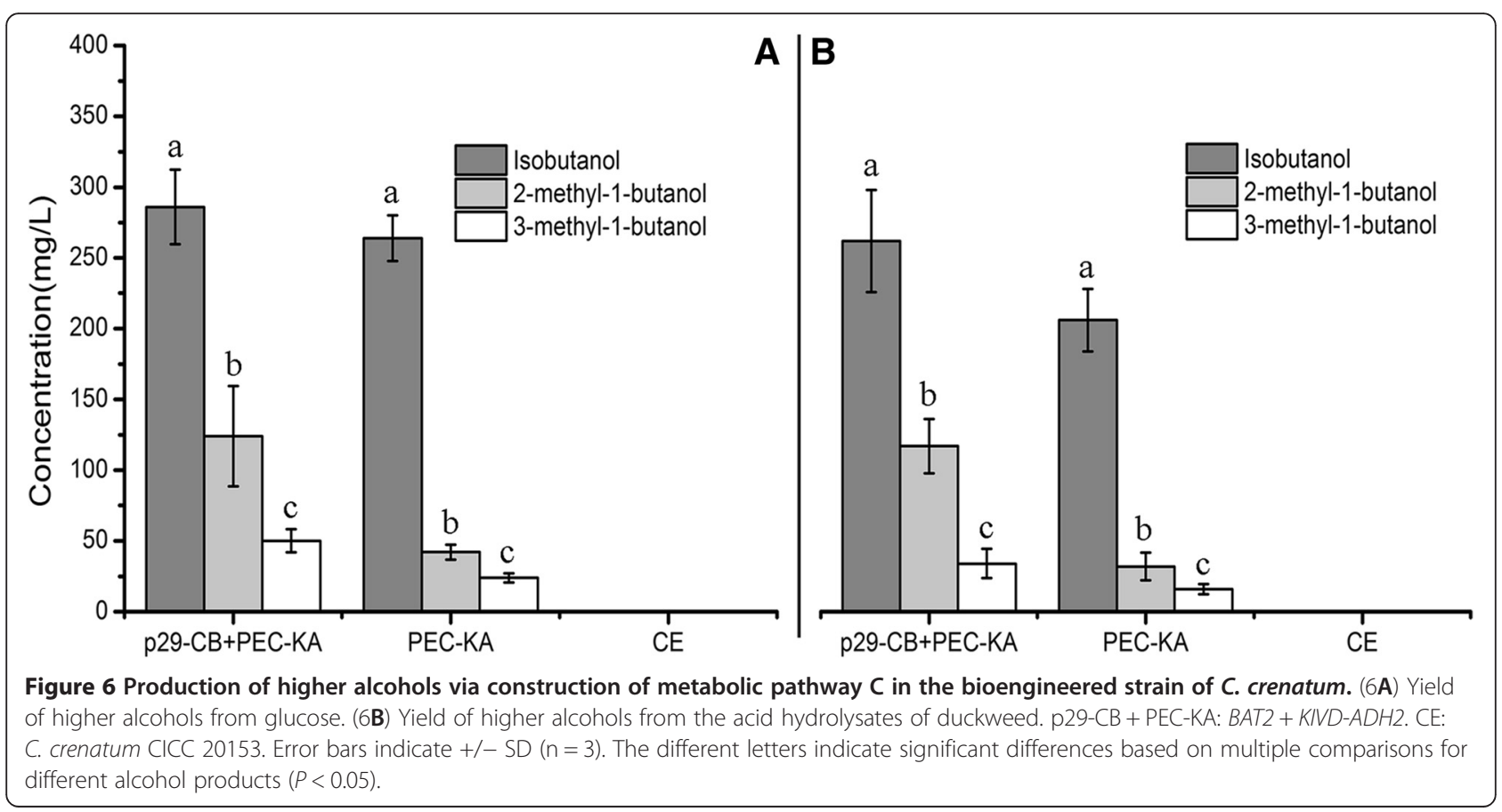


genes LEU4-LEU1 (p29-DLL) were overexpressed into the host $C$ crenatum (Figure 7 ). The maximum yield of 3-methyl-1-butanol was $748.35 \mathrm{mg} / \mathrm{L}$ from glucose substrates (Figure 7A, Table 4) and $684.79 \mathrm{mg} / \mathrm{L}$ from duckweed (Figure 7B). However, the yield dropped to $400 \mathrm{mg} / \mathrm{L}$ when only the gene LEU4 (p29-DL) was overexpressed (Figure 7A). We also surveyed the production of other higher alcohols such as isobutanol and 2methyl-1-butanol via this pathway; when only the gene LEU4 was introduced, isobutanol and 2-methyl-1-butanol yields did not improve, compared to the use of only a vector (PEC-KA). The yield of 3-methyl-1-butanol improved significantly when the two genes LEU4-LEU1 were introduced, but isobutanol and 2-methyl-1-butanol production did not change. With respect to metabolic pathway E, introducing only the gene LEU1 (p29-FL) into C. crenatum yielded $146.47 \mathrm{mg} / \mathrm{L}$ of 3-methyl-1-butanol from glucose (Figure 8A) and $129.18 \mathrm{mg} / \mathrm{L}$ from duckweed (Figure 8B).

Overall, we showed that different yields of higher alcohols can be obtained by using yeast genes to construct new metabolic pathways in C. crenatum, and the bioengineered strain can successfully ferment duckweed hydrolysates to produce higher alcohols.

\section{Discussion}

In this study, we engineered $C$. crenatum to induce the ability for higher alcohol production, and to further tap the potential capacity of this bioengineered strain for producing higher-chain alcohols such as isobutanol, 2methyl-1-butanol and 3-methyl-1-butanol from the hydrolysates of duckweed. A key objective was to highlight the potential for using this host to construct higher alcohol production platforms. This is the first time we investigated the production of higher alcohols using $C$. crenatum as the expression host.

A body of research has demonstrated over recent years that major technical breakthroughs in metabolic engineering have enabled enormous progress in the production of higher alcohols, namely by building new metabolic pathways in bioengineered microbial hosts [43]. An important determinant of success is the identification of an appropriate host to express the relevant target genes. Although efforts to construct bioengineered strains of microorganisms such as E. coli and C. glutamicum to produce isobutanol have been successful-using the genes alsS from Bacillus subtilis and ilvC and ilvD from E.coli $[10,44]$ - no attempts that we know of have been published using other enzymes to engineer corynebacterium. In order to obtain high yield of higher alcohols as much as possible, we try to develop relevant enzymes from other sources. In this paper, we made the first investigation to use yeast genes to build the metabolic pathways in C. crenatum for higher alcohol production. We constructed five metabolic pathways using genes from the isoleucine and leucine metabolic

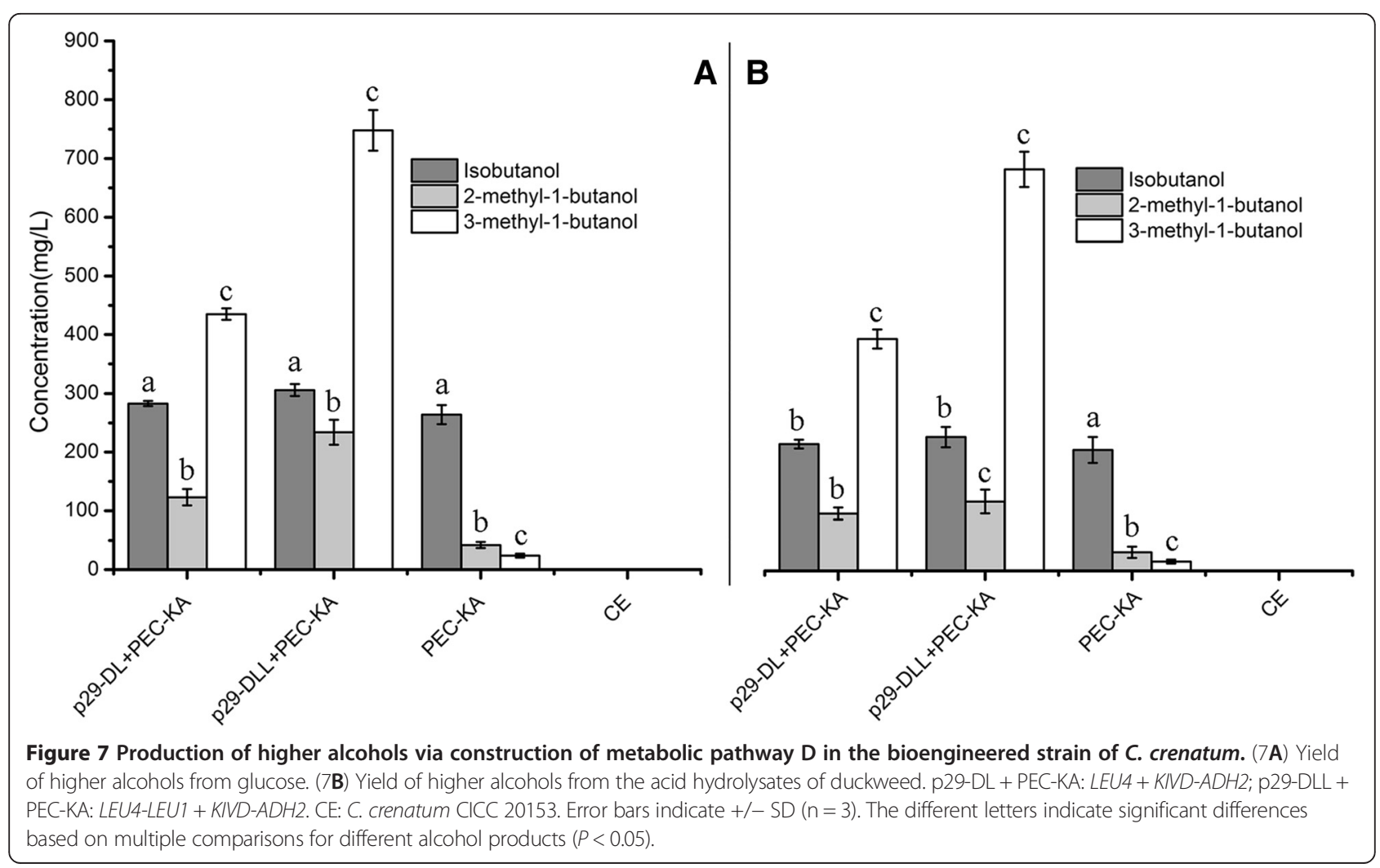




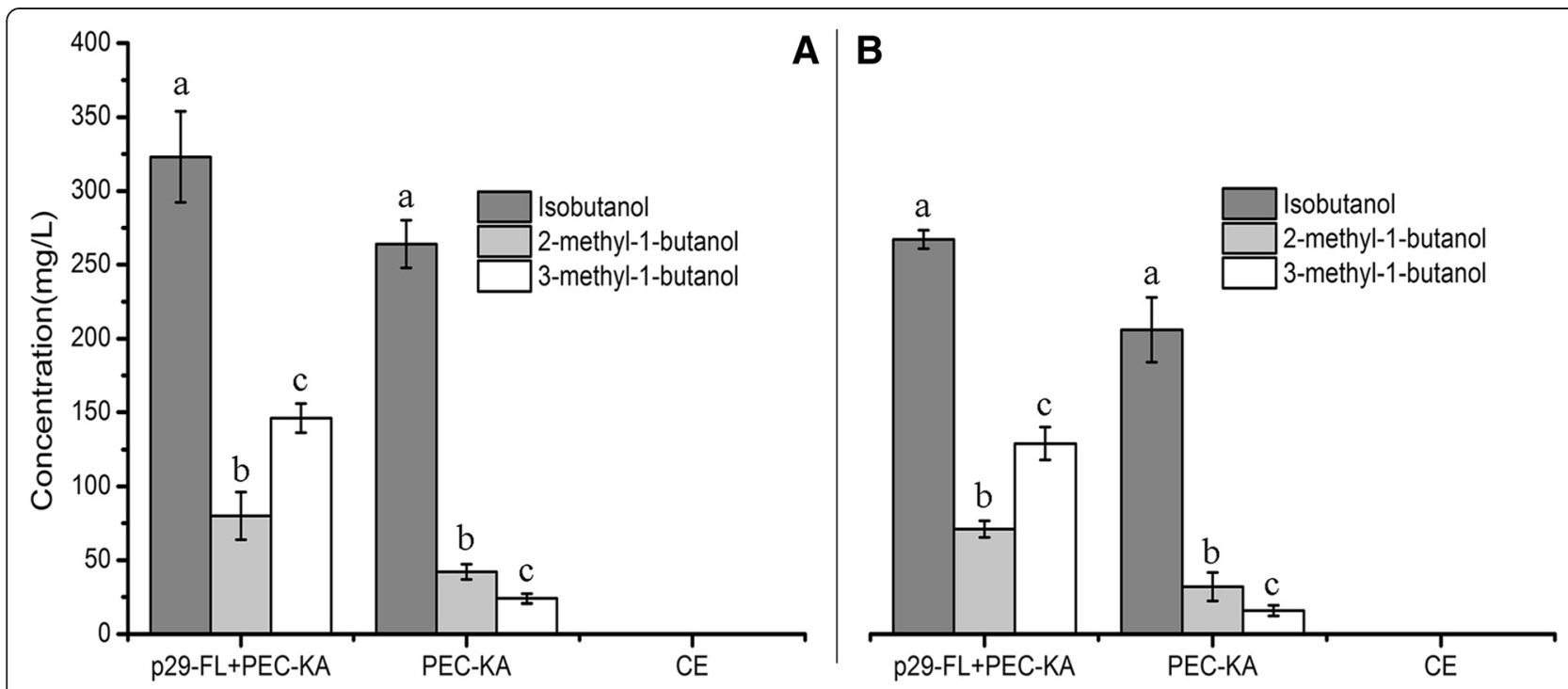

Figure 8 Production of higher alcohols via construction of metabolic pathway $E$ in the bioengineered strain of $C$. crenatum. (8A) Yield of higher alcohols from glucose. (8B) Yield of higher alcohols from the acid hydrolysates of duckweed. p29-FL + PEC-KA: LEU1 + KIVD-ADH2;. CE: C. crenatum CICC 20153. Error bars indicate +/- SD $(n=3)$. The different letters indicate significant differences based on multiple comparisons for different alcohol products $(P<0.05)$.

pathways of S. cerevisiae to produce higher alcohols. We investigated whether each pathway was capable of ultimately generating the desired end product, higher alcohols. The results showed that the bacterium C. crenatum can be used as an ideal expression host for producing alcohols using yeast genes, and that it has a strong ability to produce a wide range of long-chain alcohols.

Our findings demonstrate that the five metabolic pathways can prompt bioengineered strains to produce higher alcohols, with different pathways yielding the maximal production of the various desired products. For metabolic pathway A, the bioengineered strain with (p29-AL) + (PEC-KA) produced almost double the yield of 2-methyl1-butanol compared to results with only PEC-KA, triple the yield of 2-methyl-1-butanol yield with (p29-ALI + PEC-KA) compared to (p29-AL) + (PEC-KA), and double the 2-methyl-1-butanol yield with (p29-ALII) + (PEC-KA) compared to (p29-ALI) + (PEC-KA) - that is, the tendency was the same, whether the substrate was glucose or duckweed (Figure 4A,B). For metabolic pathway B, the yield of isobutanol did not increase when two vectors were used (p29-BI) + (PEC-KA) compared to only PEC-KA, while production of isobutanol tripled from (p29-BI) + (PEC$\mathrm{KA})$ to (p29-BII) + (PEC-KA), and doubled from (p29$\mathrm{BII})+(\mathrm{PEC}-\mathrm{KA})$ to $(\mathrm{p} 29-\mathrm{BIII})+(\mathrm{PEC}-\mathrm{KA})$, a conclusion confirmed by Figure $5(\mathrm{~A}, \mathrm{~B})$. For metabolic pathway D, the change from using one (PEC-KA) to two vectors (p29-DL + PEC-KA) in the bioengineered strain tripled the yield of 3-methyl-1-butanol, but the change from (p29-DL) + (PEC-p29) to (p29-DLL) + (PEC-KA) caused the yield of 3-methyl-1-butanol to decline by $50 \%$
(Figure 7A,B). These results showed clearly that it is feasible to use $C$. crenatum as a host to bioengineer strains to produce higher alcohols, and also showed its potential as a bioengineered platform for producing biofuel.

As duckweed is a new kind of energy crop, some preliminary studies have been conducted using its hydrolysates to produce higher alcohols by microbial transformation [20]. Those results illustrated that duckweed has very high energy efficiency for producing biofuels that contain higher alcohols such as butanol and 2-methyl-1-butanol, identifying its great potential for use as an industrial feedstock in the production of biofuels as alternative energy. Further research and development should concentrate on the production of higher alcohols via fermentation of duckweed by appropriate microorganisms. Our research provides a foundation for the development of industrialized biofuel production using duckweed. However, the yields of higher alcohols from duckweed are extremely low (especially $\mathrm{C}_{5}$ alcohols such as 2-methyl-1-butanol and 3-methyl-1-butanol), making it necessary to develop an optimal host as a cell factory to match the fermentation substrate of duckweed, in order to obtain the highest possible yields. In this paper, in order to rudimentarily evaluate the ability of this engineered host for fermenting duckweed to produce alcohols, we chose preferentially acid hydrolysates of duckweed as fermentation substrate, rather than eznymatic hydrolysates. We suppose if this engineered strains can ferment acid hydrolysate with inhibitors, then it can certainly ferment enzymatic hydrolysate without inhibitors, because formation of inhibitors from acid hydrolysis would likely inhibit the gowth of bacterium, lead to inefficiency of 
fermentation. Our results confirmed that it is feasible to bioengineer $C$. crenatum, via the construction of new metabolic pathways with yeast genes, to ferment acid hydrolysates of duckweed to produce higher alcohols. Each individual metabolic pathway that we tested generated similar results using glucose or duckweed. Notably, the desired results were achieved only when multiple exogenous genes were overexpressed at the same time.

Each metabolic pathway led to the production of higher alcohols by its corresponding bioengineered strain, and seemingly generated greater yields of higher alcohols using glucose as the fermentation substrate versus duckweed. However, statistical comparison of yields from the two different fermentation substrates, on the whole showed that the yield of each kind of higher alcohol from duckweed was not significantly lower than the yield from glucose (Figure 4 Figure $8, P<0.05$ ). For example, there were almost no differences for 2-methyl-1-butanol (Figure 4A, B). This showed that the presence of some anti-nutritive compounds in the acid hydrolysates of duckweed did not significantly inhibit the growth of bioengineered C. crenatum, enabling nearly equal yields compared to those from glucose under the same fermentation conditions. This conclusion was confirmed when we tested for the presence of inhibitors from acid hydrolysate of duckweed, including furfural, hydroxymethylfurfural (HMF) and other phenols reported to affect fermentation [45]. In this experiments, only furfural and HMF were detected (Table 5). Comparison of fermentation results via two substrates confirmed the low levels of inhibitors detected in the pretreated substrate (furfural and HMF) do not significantly inhibit bacterial growth or production, also showed inhibitors concentrations were below levels to disrupt the growth of $C$. crenatum.

Overall, our analyses demonstrate that duckweed has potential as a biofuel crop, even more so than plants currently used for cost-saving, environment-friendly purpose, such as corn or cassava. In fact, duckweed would be even more promising for producing higher alcohols if further developments can be achieved by constructing even more effective bioengineered hosts.

The combined results of this study suggest that although the genetic background of $C$. crenatum is not clear, its genome-scale metabolic network is similar to that of C. glutamicum because it is a homologous strain. Thus, the genetic tools used for metabolic engineering of C. glutamicum, and experience gained in the development and utilization of that species, can inform the production of higher alcohols using C. crenatum as a host platform. Lessons can also be drawn from the metabolic pathways of carbon flow in C. glutamicum to produce higher alcohols.

\section{Conclusions}

In summary, it is clearly feasible to use C. crenatum as a host to bioengineer strains with efficacious abilities for
Table $\mathbf{5}$ Inhibitor determination from acid hydrolysates of duckweed

\begin{tabular}{ll}
\hline Compound & Inhibitor concentration $\mathbf{( m g / L )}$ \\
\hline Furfural & $19.65 \pm 0.81$ \\
Hydroxymethylfurfural (HMF) & $3.89 \pm 0.25$ \\
Glucuronic acid & ND \\
p-coumaric acid & ND \\
Syringic acid & ND \\
Ferulic acid & ND \\
\hline
\end{tabular}

ND: Not detected.

producing higher alcohols. We report here the first attempt to use $C$. crenatum for this purpose. Our experiments showed that effectively expressing metabolic enzymes in combinations that are associated with higher alcohol production in the metabolic pathways of $S$. cerevisiae led to accumulation of the precursor of amino acids, which enabled genetic engineering of the strain to produce higher alcohols. Our experimental results will facilitate further development of this host to produce higher alcohols. Our results also showed that duckweed plants represent an ideal fermentation substrate for the development of higher alcohols. This provides a solid foundation for the use of duckweed as the next generation of alternative energy feedstocks.

\section{Competing interests}

The authors declare that they have no competing interests.

\section{Authors' contributions}

HS participated in the conception, design, data collection and analysis, and drafted the manuscript. FJJ assisted the laboratory work, results interpretation and the manuscript revision. QL, ZZ, TX participated in the partial discussion of the results and revised the manuscript. All authors read and approved the final manuscript. $\mathrm{HZ}, \mathrm{MW}$ conceived the original idea and MW directed the research.

\section{Acknowledgments}

The authors gratefully acknowledge the support of the organizations who funded this work: the National '863' Programme (No.2011AA10A10401), the Knowledge Innovation Program of the Chinese Academy of Sciences (No. KSCX1-YW-11C4), and the 12th "five-year" key task project in crop breeding of Sichuan Province (SN: 2011yzgg05).

Received: 15 November 2014 Accepted: 26 January 2015

Published online: 07 February 2015

\section{References}

1. Smith KM, Cho KM, Liao JC. Engineering Corynebacterium glutamicum for isobutanol production. Appl Microbiol Biotechnol. 2010;87(3):1045-55.

2. Ni Y, Sun Z. Recent progress on industrial fermentative production of acetone-butanol-ethanol by Clostridium acetobutylicum in China. Appl Microbiol Biotechnol. 2009;83(3):415-23.

3. Ishola MM, Jahandideh A, Haidarian B, Brandberg T, Taherzadeh MJ. Simultaneous saccharification, filtration and fermentation (SSFF): a novel method for bioethanol production from lignocellulosic biomass. Bioresour Technol. 2013;133:68-73.

4. Wang J, Wan W. Comparison of different pretreatment methods for enriching hydrogen-producing bacteria from digested sludge. Int J Hydrogen Energy. 2008;33(12):2934-41. 
5. Tuo H. Thermal-economic analysis of a transcritical Rankine power cycle with reheat enhancement for a low-grade heat source. Int J Energy Res. 2013;37(8):857-67.

6. Zheng S, Jiang W, Cai Y, Dionysiou DD, O'Shea KE. Adsorption and photocatalytic degradation of aromatic organoarsenic compounds in $\mathrm{TiO} 2$ suspension. Catal Today. 2014;224:83-8.

7. Wang L, Luo Z, Shahbazi A. Optimization of simultaneous saccharification and fermentation for the production of ethanol from sweet sorghum (Sorghum bicolor) bagasse using response surface methodology. Ind Crops Prod. 2013:42:280-91.

8. Mainguet SE, Liao JC. Bioengineering of microorganisms for $C(3)$ to $C(5)$ alcohols production. Biotechnol J. 2010;5(12):1297-308.

9. Atsumi S, Liao JC. Metabolic engineering for advanced biofuels production from Escherichia coli. Curr Opin Biotechnol. 2008;19(5):414-9.

10. Su H, Zhao Y, Zhao H, Wang M, Li Q, Jiang J, et al. Identification and assessment of the effects of yeast decarboxylases expressed in Escherichia coli for producing higher alcohols. J Appl Microbiol. 2014;17(1):126-38.

11. Wang Z, Cao G, Jiang C, Song J, Zheng J, Yang Q. Butanol production from wheat straw by combining crude enzymatic hydrolysis and anaerobic fermentation using Clostridium acetobutylicum ATCC824. Energy Fuel. 2013;27(10):5900-6.

12. Clomburg JM, Gonzalez R. Biofuel production in Escherichia coli: the role of metabolic engineering and synthetic biology. Appl Microbiol Biotechnol. 2010;86(2):419-34.

13. Crutcher FK, Parich A, Schuhmacher R, Mukherjee PK, Zeilinger S, Kenerley CM. A putative terpene cyclase, vir4 is responsible for the biosynthesis of volatile terpene compounds in the biocontrol fungus Trichoderma virens. Fungal Genet Biol. 2013;56:67-77.

14. Wang W, Liu X, Lu X. Engineering cyanobacteria to improve photosynthetic production of alka (e) nes. Biotechnol Biofuels. 2013;6:69.

15. Choi YJ, Lee SY. Microbial production of short-chain alkanes. Nature. 2013;502:571-4.

16. Stomp A-M. The duckweeds: a valuable plant for biomanufacturing. In: El-Gewely MR, editor. Biotechnol Annual Rev, vol. 11. Amsterdam of Holland: Elsevier; 2005. p. 69-99.

17. McCombs PJ, Ralph RK. Protein, nucleic acid and starch metabolism in the duckweed, Spirodela oligorrhiza, treated with cytokinins. Biochem J. 1972;129(2):403-17.

18. $\mathrm{Xu} J$, Zhao H, Stomp A-M, Cheng JJ. The production of duckweed as a source of biofuels. Biofuels. 2012;3:589-601.

19. Chen Q, Jin Y, Zhang G, Fang Y, Xiao Y, Zhao H. Improving Production of Bioethanol from Duckweed (Landoltia punctata) by Pectinase Pretreatment. Energies. 2012;5(12):3019-32.

20. Su H, Zhao Y, Jiang J, Lu Q, Li Q, Luo Y, et al. Use of duckweed (Landoltia punctata) as a fermentation substrate for the production of higher alcohols as biofuels. Energy Fuel. 2014;28(5):3206-16.

21. Miller E, Turner P, Jarboe L, Ingram L. Genetic changes that increase 5hydroxymethyl furfural resistance in ethanol-producing Escherichia coli LY180. Biotechnol Lett. 2010;32(5):661-7.

22. Geddes CC, Mullinnix M, Nieves I, Peterson J, Hoffman R, York S, et al. Simplified process for ethanol production from sugarcane bagasse using hydrolysate-resistant Escherichia coli strain MM160. Bioresour Technol. 2011;102(3):2702-11.

23. Baez A, Cho K-M, Liao JC. High-flux isobutanol production using engineered Escherichia coli: a bioreactor study with in situ product removal. Appl Microbiol Biotechnol. 2011;90(5):1681-90.

24. Atsumi S, Wu TY, Machado IM, Huang WC, Chen PY, Pellegrini M, et al. Evolution, genomic analysis, and reconstruction of isobutanol tolerance in Escherichia coli. Mol Syst Biol. 2010;6(1):98.

25. Zhang S. Research of fermentation Leucine by Corynebacterium crenatum. Microbiology. 1989;5:264-7 [in Chinese].

26. Zhang S, Lu D. The breeding of leucine producing mutant strains, and fermentation conditions. Acta Microbiol Sin. 1979;2:180-6 [in Chinese].

27. Xu M, Rao Z, Yang J, Xia H, Dou W, Jin J, et al. Heterologous and homologous expression of the arginine biosynthetic $\arg \mathrm{C} \sim \mathrm{H}$ cluster from Corynebacterium crenatum for improvement of $(\mathrm{L})$-arginine production. J Ind Microbiol Biotechnol. 2012;39(3):495-502.

28. Tang R, Guo Y, Chen Q. Isoleucine fermentation research: isoleucine fermentation production directly with sugar raw materials. Acta Microbiol Sin. 1978;18(1):45-51 [in Chinese].
29. Eggeling L, Bott M. Handbook of Corynebacterium glutamicum. Boca Raton, USA: CRC press; 2010.

30. Haynes JA, Britz ML. The effect of growth conditions of Corynebacterium glutamicum on the transformation frequency obtained by electroporation. J General Microbiol. 1990;136(2):255-63.

31. Van der Rest $M$, Lange C, Molenaar D. A heat shock following electroporation induces highly efficient transformation of Corynebacterium glutamicum with xenogeneic plasmid DNA. Appl Microbiol Biotechnol. 1999;52(4):541-5.

32. Rose R, Rose CL, Omi SK, Forry KR, Durall DM, Bigg WL. Starch determination by perchloric acid vs enzymes: evaluating the accuracy and precision of six colorimetric methods. J Agric Food Chem. 1991;39(1):2-11.

33. Pirt SJ, Whelan WJ. The determination of starch by acid hydrolysis. J Sci Food Agric. 1951;2(5):224-8.

34. Thiex NJ, Manson H, Anderson S, Persson J-Å. Determination of crude protein in animal feed, forage, grain, and oilseeds by using block digestion with a copper catalyst and steam distillation into boric acid: collaborative study. J AOAC Int. 2002;85(2):309-17.

35. Xiao $Y$, Fang $Y$, Jin $Y$, Zhang G, Zhao $H$. Culturing duckweed in the field for starch accumulation. Ind Crops Prod. 2013;48:183-90.

36. Viles FJ, Silverman L. Determination of starch and cellulose with anthrone. Anal Chem. 1949;21(8):950-3.

37. Hansen J, Møller I. Percolation of starch and soluble carbohydrates from plant tissue for quantitative determination with anthrone. Anal Biochem. 1975;68(1):87-94.

38. Black $\mathrm{H}$. Determination of sodium carboxymethylcellulose in detergent mixtures by anthrone method. Anal Chem. 1951;23(12):1792-5.

39. liyama K, Wallis AF. Determination of lignin in herbaceous plants by an improved acetyl bromide procedure. J Sci Food Agric. 1990;51(2):145-61.

40. liyama $K$, Wallis AFA. An improved acetyl bromide procedure for determining lignin in woods and wood pulps. Wood Sci Technol. 1988;22 (3):271-80.

41. Lee HS, Rouseff RL, Nagy S. HPLC determination of furfural and 5hydroxymethylfurfural in citrus juices. J Food Sci. 1986;51(4):1075-6.

42. Theobald A, Müller A, Anklam E. Determination of 5-hydroxymethylfurfural in vinegar samples by HPLC. J Agric Food Chem. 1998;46(5):1850-4.

43. Connor MR, Liao JC. Microbial production of advanced transportation fuels in non-natural hosts. Curr Opin Biotechnol. 2009;20(3):307-15.

44. Brynildsen MP, Liao JC. An integrated network approach identifies the isobutanol response network of Escherichia coli. Mol Syst Biol. 2009;5:277.

45. Wimalasena TT. Phenotypic characterisation of Saccharomyces spp. yeast for tolerance to stresses encountered during fermentation of lignocellulosic residues to produce bioethanol. Microb Cell Fact. 2014;13:47.

\section{Submit your next manuscript to BioMed Central and take full advantage of:}

- Convenient online submission

- Thorough peer review

- No space constraints or color figure charges

- Immediate publication on acceptance

- Inclusion in PubMed, CAS, Scopus and Google Scholar

- Research which is freely available for redistribution 